\title{
Impaired left ventricular filling dynamics in patients with angina and angiographically normal coronary arteries: effect of $\beta$ adrenergic blockade
}

G Fragasso, S L Chierchia, G Pizzetti, E Rossetti, M Carlino, S Gerosa, O Carandente, A Fedele, $\mathbf{N}$ Cattaneo

drome remains elusive, though most groups believe that abnormalities of the coronary microcirculation are involved..$^{2-6}$

Of the many aspects which have been investigated, those related to left ventricular function have provided conflicting results. $.^{2-4} 7-12$ In fact, though systolic function is usually normal both at rest and after exercise, isolated reports have suggested the presence of left ventricular diastolic dysfunction. ${ }^{89}$ However, it is still unknown whether left ventricular diastolic function is consistently affected in SX patients and, if so, whether it may be improved by pharmacological interventions. Therefore, we assessed exercise performance and resting left ventricular filling dynamics in a group of SX patients treated with placebo or atenolol for 10 days and, for comparison, in a group of healthy controls and in a group of patients with coronary artery disease (CAD).

Results-Unlike the controls, patients with SX and those with CAD consistently showed exercise-induced ST segment abnormalities and impaired resting left ventricular filling while on placebo. Atenolol significantly reduced episodes of angina, completely prevented exerciseinduced ST segment changes in $18 \mathrm{SX}$ patients, and delayed their onset in all patients with CAD: in both groups the agent significantly improved Dopplerderived indices (mean (SD)) of ventricular filling (E/A 0.97 (0.27) $v 1.22(0.32)$ and $0.84(0.21) v 1.19(0.37)$, respectively).

Conclusions-The objective documentation of left ventricular filling abnormalities may be useful in confirming the clinical diagnosis of $\mathbf{S X}$ and in providing objective evidence of therapeutic benefit. The similarity of the symptoms and electrocardiographic and ventricular filling abnormalities found in patients with SX

Division of Cardiology, Istituto Scientifico $\mathbf{H}$ San Raffaele, Milan, Italy G Fragasso

S L Chierchia

G Pizzetti

E Rossetti

M Carlino

$S$ Gerosa

O Carandente

A Fedele

N Cattaneo

Correspondence to: Dr G Fragasso, Division of Cardiology, Istituto Scientifico H San Raffaele, Via Olgettina, 60-20132 Milan, Italy.

Accepted for publication 23 July 1996 and in those with CAD suggests that ischaemia is involved in both groups.

(Heart 1997;77:32-39)

Keywords: left ventricular filling; syndrome $\mathrm{X} ; \boldsymbol{\beta}$ blockers; diastolic function

Syndrome $\mathrm{X}(\mathrm{SX})$ is a clinical definition that identifies patients with typical angina, a positive exercise test, and angiographically smooth epicardial coronary arteries. ${ }^{1}$ Despite the considerable number of studies performed in recent years, the pathophysiology of this syn-

\section{Patients and methods}

STUDY POPULATION

We studied 22 consecutive patients (16 females, age 53 (4), range 38-70) with rest and/or effort angina, a reproducibly positive exercise test $(>1 \mathrm{~mm}$ planar or downsloping ST segment depression) and angiographically smooth epicardial coronary arteries. In all of them prolonged hyperventilation and/or ergonovine administration, performed during coronary arteriography, failed to induce spasm.

We also studied 10 patients with chronic, stable, effort angina; no clinical or electrocardiographic evidence of old myocardial infarction; and angiographically documented coronary artery disease (two women, mean age 55 (8), range 45-72). Finally, we studied 13 subjects (nine women, mean age 52 (5) years, range 41-66) undergoing routine cardiological evaluation before general surgery. In all of them physical examination, chest $x$ ray, resting and exercise ECG, and two dimensional echocardiographic and Doppler studies were normal. In all groups, subjects were age matched and had no diabetes, hypertension, overt left ventricular hypertrophy, pericardial or valve disease, or cardiomyopathy.

Each patient and control subject gave written informed consent to the study.

\section{STUDY DESIGN}

With the exception of coronary arteriography, which was obviously not performed in the controls without heart disease, the protocol was similar in all study subjects. After coronary 
Table 1 Resting heart rate (HR), systolic (SBP), and diastolic blood pressure (DBP) (mean $(S D)$ ) in syndrome $X(S X)$, coronary disease patients (CAD), and controls on placebo $(P)$, atenolol $(A)$, and acute propranolol $(A P)$

\begin{tabular}{|c|c|c|c|}
\hline & $\begin{array}{l}\text { HR } \\
\text { (beats/min) }\end{array}$ & $\begin{array}{l}S B P \\
(m m \mathrm{Hg})\end{array}$ & $\begin{array}{l}D B P \\
(m m \mathrm{Hg})\end{array}$ \\
\hline \multicolumn{4}{|c|}{ Controls: } \\
\hline $\mathbf{P}$ & 79 (12) & $120(13)$ & $80(6)$ \\
\hline A & $56(10)$ & $110(16)$ & $75(7)$ \\
\hline AP & $54(7)$ & $112(10)$ & 74 (9) \\
\hline \multicolumn{4}{|l|}{ SX: } \\
\hline$P$ & $75(10)$ & $123(15)$ & $82(7)$ \\
\hline A & $56(9)$ & 118 (19) & $78(9)$ \\
\hline $\mathrm{AP}$ & $58(7)$ & $120(19)$ & $80(8)$ \\
\hline \multicolumn{4}{|l|}{ CAD: } \\
\hline $\mathbf{P}$ & $84(12)$ & $135(20)$ & $85(10)$ \\
\hline A & $59(5)$ & $132(26)$ & $81(9)$ \\
\hline AP & $60(7)$ & $130(18)$ & $80(6)$ \\
\hline
\end{tabular}

Significance levels are given in the text.

arteriography (if performed) patients and controls were blindly and randomly assigned to a 10 day treatment period with either placebo or atenolol (100 mg daily) and then crossed over to the other regimen for 10 more days. During each study period, patients were asked to record in a diary the occurrence of chest pain episodes. At the end of each treatment period exercise testing and echocardiographic and Doppler evaluation of left ventricular function were performed.

\section{EXERCISE TESTING}

Treadmill exercise testing was performed according to the modified Bruce protocol; the 12-lead ECG and the blood pressure (cuff sphygmomanometer) were recorded at rest and every minute during exercise and recovery.

The following criteria were used for stopping the test: (1) achievement of the maximal predicted heart rate; $(2)$ diagnostic $(>1.0 \mathrm{~mm}$ rectilinear or downsloping) ST segment depression on at least one precordial or two peripheral ECG leads, with or without angina; (3) severe dyspnoea or fatigue; (4) repetitive ventricular arrhythmias; (5) a greater than 10 $\mathrm{mm} \mathrm{Hg}$ decrease in systolic blood pressure at any exercise step.

For all tests, the following variables were noted: (1) total exercise time; (2) time to $1 \mathrm{~mm}$ ST segment depression; (3) recovery time; (4) rate-pressure product at $1 \mathrm{~mm} \mathrm{ST}$ segment depression; (5) rate-pressure product at peak exercise.

\section{ECHOCARDIOGRAPHY}

All study subjects had adequate transthoracic acoustic windows. A phase-array ultrasound system (Sonos 500, Hewlett Packard,
Andover, Massachussets) was used for $M$ mode, cross sectional, and pulsed wave Doppler echocardiographic studies. This instrument combines a pulsed Doppler flow analyser with a $2.5 \mathrm{MHz}$ transducer (twodimensional $90^{\circ}$ angle electronic sector scanner) and allows positioning of the Doppler sample volume anywhere in the two-dimensional sector plane by a movable cursor. Left ventricular diastolic flow velocity was measured at depths ranging from 9 to $13 \mathrm{~cm}$. The Doppler output of diastolic flow velocity is available both as an audio signal and as a spectral display. Flow velocity profiles appear as waveforms composed of small individual grey and black blocks: they are displayed on a TV screen simultaneously with a lead II electrocardiogram and recorded on VHS tape.

Each subject was examined in the left lateral decubitus position with respiration suspended in the shallow expiratory phase. Standard $M$ mode measurements were obtained at the papillary muscle level. Left ventricular mass was calculated by Devereux and Reichek's formula $^{13}$ and normalised for body surface (left ventricular mass index (LVMI) $\mathrm{g} / \mathrm{m}^{2}$ ). Ejection fraction was calculated by the Teichholz method. ${ }^{14}$

At rest, wall motion was assessed in standard parasternal and apical views. After exercise, only the apical views were obtained within one minute of the end of the test. Images were reviewed by three independent experienced echocardiographers who were unaware of patients' clinical status.

Doppler measurements were performed at rest, immediately after the study of wall motion at the end of exercise, again when the ECG and heart rate had returned to baseline, and after 4 and 24 hours. The apical four chamber view, optimised to visualise the left ventricular cavity and the maximal excursion of the mitral valve leaflets was used. The cursor line was positioned through a plane traversing the left ventricle from apex to mitral valve annulus. Care was taken in obtaining the smallest possible angle between the direction of diastolic blood flow and the orientation of the ultrasonic beam. The sample volume ( $5 \mathrm{~mm}$ in axial length) was positioned in the inflow area of the left ventricle between the mitral leaflet tips, and its position along the cursor line was adjusted until the highest early and late peaks of diastolic flow velocity were recorded and the graphic quality of the Doppler waveform was optimal.

Table 2 Exercise variables (mean (SD)) in syndrome $X(S X)$, coronary disease patients (CAD), and controls on placebo $(P)$ and atenolol $(A)$

\begin{tabular}{|c|c|c|c|c|c|}
\hline & $\begin{array}{l}\text { Time to } \\
1 \mathrm{~mm}(\mathrm{~s})\end{array}$ & $\begin{array}{l}\text { Time to peak } \\
\text { exercise }(s)\end{array}$ & $\begin{array}{l}R P P \text { at } 1 \mathrm{~mm} S T \downarrow \\
\text { (beats } / \text { min } \times \mathrm{mm} \mathrm{Hg} \text { ) }\end{array}$ & $\begin{array}{l}R P P \text { at peak exercise } \\
\text { (beats } / \text { min } \times \mathrm{mm} \mathrm{Hg} \text { ) }\end{array}$ & $\begin{array}{l}\text { Recovery time } \\
\text { (s) }\end{array}$ \\
\hline \multicolumn{6}{|l|}{ Controls: } \\
\hline $\mathrm{P}$ & - & $958(130)$ & - & $28890(3676)$ & - \\
\hline A & - & 960 (133) & - & $17083(2747)$ & - \\
\hline \multicolumn{6}{|c|}{ (2) } \\
\hline P & $717(102)$ & $868(122)$ & $20792(4107)$ & $24777(3736)$ & $250(176)$ \\
\hline \multicolumn{6}{|l|}{ CAD: } \\
\hline$P$ & $452(247)$ & $508(223)$ & $17480(2870)$ & $19190(3980)$ & $642(286)$ \\
\hline A & $529(213)$ & $681(205)$ & $14179(1941)$ & $15568(2284)$ & $420(221)$ \\
\hline
\end{tabular}

RPP, rate-pressure product. at $1 \mathrm{~mm}$ ST depression being higher than those obtained at peak exercise, which were calculated in all 22 patients. 
Table 3 Maximal early (E) and late $(A)$ diastolic flow velocities and their ratio $(E / A)$, early (SE) late $\left(\int A\right)$ and total $(S T)$ time/velocity integrals, and atrial contribution (AC) to left ventricular filling, in syndrome $X(S X)$, coronary disease patients (CAD), and controls (mean (SD)). Measurements were obtained on placebo $(P)$, atenolol $(A)$, and acute propranolol $(A P)$

\begin{tabular}{|c|c|c|c|c|c|c|c|c|c|}
\hline \multirow[b]{2}{*}{ Variables } & \multicolumn{3}{|l|}{ Controls } & \multicolumn{3}{|l|}{$S X$} & \multicolumn{3}{|l|}{$C A D$} \\
\hline & $P$ & $A$ & $A P$ & $P$ & $A$ & $A P$ & $P$ & $A$ & $A P$ \\
\hline $\begin{array}{l}\mathrm{E}(\mathrm{cm} / \mathrm{s}) \\
\mathrm{A}(\mathrm{cm} / \mathrm{s}) \\
\mathrm{E} / \mathrm{A} \\
\int \mathrm{E}(\mathrm{cm}) \\
\int A(\mathrm{~cm}) \\
\int T(\mathrm{~cm}) \\
\mathrm{AC}(\%)\end{array}$ & $\begin{array}{l}86(15) \\
58(10) \\
1 \cdot 51(0 \cdot 28) \\
12 \cdot 9(4 \cdot 7) \\
5 \cdot 8(2 \cdot 2) \\
21 \cdot 6(5 \cdot 6) \\
27(5)\end{array}$ & $\begin{array}{l}85(16) \\
52(15) \\
1 \cdot 53(0 \cdot 20) \\
12 \cdot 1(2 \cdot 4) \\
4 \cdot 9(1 \cdot 5) \\
23 \cdot 2(5 \cdot 1) \\
21(6)\end{array}$ & $\begin{array}{l}83(11) \\
57(6) \\
1 \cdot 46(0 \cdot 26) \\
12 \cdot 5(3 \cdot 8) \\
5 \cdot 2(1 \cdot 8) \\
20 \cdot 8(2 \cdot 9) \\
25(7)\end{array}$ & $\begin{array}{l}63(14) \\
67(14) \\
0.97(0 \cdot 27) \\
9 \cdot 5(2 \cdot 3) \\
6 \cdot 4(1 \cdot 3) \\
17 \cdot 9(3 \cdot 6) \\
38(9)\end{array}$ & $\begin{array}{l}75(17) \\
63(15) \\
1 \cdot 22(0 \cdot 32) \\
11 \cdot 8(3 \cdot 1) \\
6 \cdot 5(2 \cdot 3) \\
22 \cdot 4(4 \cdot 8) \\
29(9)\end{array}$ & $\begin{array}{l}65(12) \\
70(14) \\
0 \cdot 93(0 \cdot 20) \\
9 \cdot 0(2 \cdot 2) \\
7 \cdot 4(1 \cdot 1) \\
17 \cdot 8(4 \cdot 0) \\
36(6)\end{array}$ & $\begin{array}{l}64(15) \\
78(20) \\
0 \cdot 84(0 \cdot 21) \\
9 \cdot 0(3 \cdot 2) \\
7 \cdot 8(1 \cdot 9) \\
18 \cdot 9(4 \cdot 8) \\
42(11)\end{array}$ & $\begin{array}{l}75(12) \\
67(21) \\
1 \cdot 19(0 \cdot 37) \\
11 \cdot 3(1 \cdot 8) \\
6 \cdot 7(2 \cdot 7) \\
22 \cdot 9(4 \cdot 5) \\
28(7)\end{array}$ & $\begin{array}{l}66(11) \\
77(17) \\
0 \cdot 86(0 \cdot 19) \\
9 \cdot 2(3 \cdot 1) \\
7 \cdot 7(2 \cdot 2) \\
19 \cdot 1(4 \cdot 1) \\
40(8)\end{array}$ \\
\hline
\end{tabular}

See text for significance levels.

QUANTITATIVE ASSESSMENT OF DIASTOLIC FLOW VELOCITY WAVEFORMS

The flow velocity signal and the ECG were recorded on VHS tape. In each study, five waveforms with the highest diastolic flow velocity and the best signal to noise ratio were chosen for analysis. Each of the five waveforms was individually characterised quantitatively and the following measurements were obtained: maximal early diastolic flow velocity and the integral of the early peak (E); maximal late diastolic flow velocity and the integral of the late peak (A); total time/velocity integral. We also derived the ratio of maximal flow velocity in early diastole to that obtained in late diastole $(\mathrm{E} / \mathrm{A})$ and the percentage of atrial contribution to left ventricular filling (A integral/total integral).
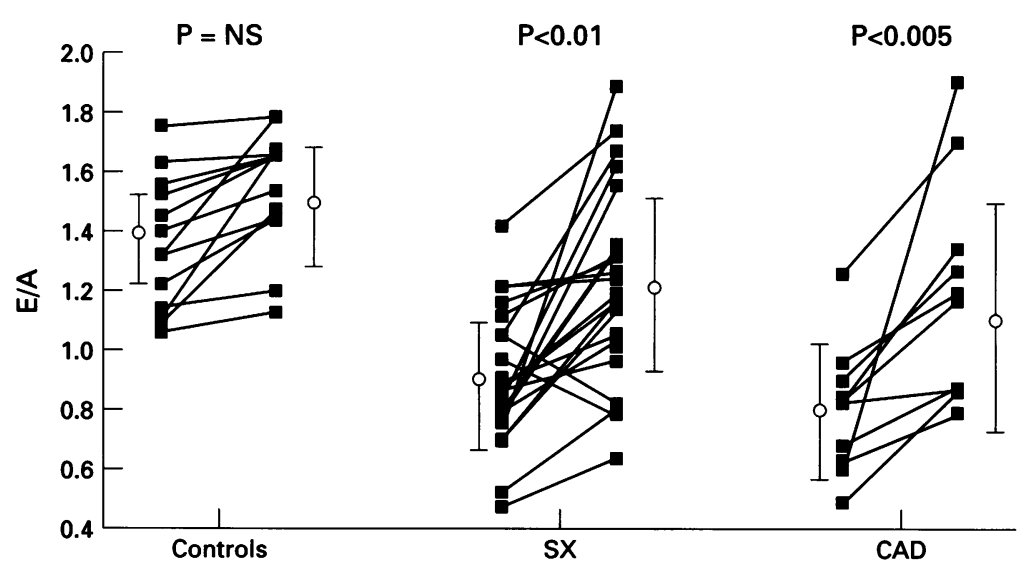

Figure 1 Individual, mean (SD), values of the E/A ratio in the three study groups. In each group the left and the right sides represent the values on placebo and after therapy with atenolol, respectively.

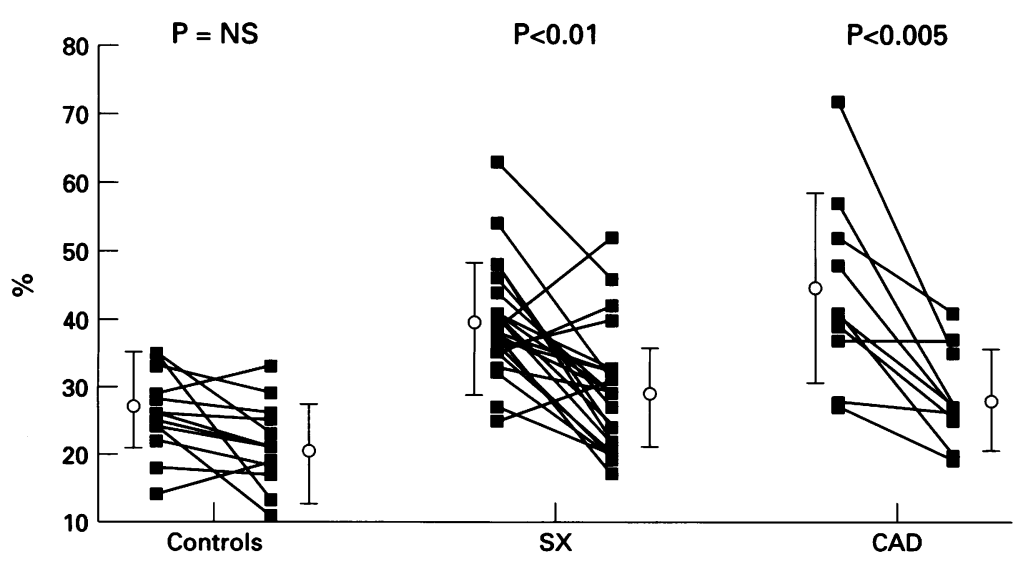

Figure 2 Individual, mean (SD), values of atrial contribution to left ventricular filling in the three study groups. In each group the left and the right sides represent the values on placebo and after therapy with atenolol, respectively.
To assess whether $\beta$-blocker-induced bradycardia could, per se, affect transmitral Doppler flow variables, all study subjects were given intravenous propranolol at the end of the wash-out period. The drug was given over 30 min and the individual dose was titrated to the heart rate response $(>30 \%$ reduction relative to the control values, average $0 \cdot 1 \mathrm{mg} / \mathrm{kg}$ ). When the target heart rate was achieved, quantitative measurements of diastolic flow velocity were again obtained.

\section{STATISTICAL ANALYSIS}

All data are expressed as mean values (SD). The number of anginal episodes during placebo and atenolol was compared by the Wilcoxon signed-rank test. Doppler variables on placebo and on atenolol and propanolol were compared by paired Student's $t$ tests. Differences were regarded as significant when $P<0.05$, after Bonferroni's correction for multiple testing.

\section{Results}

SYMPTOMS

During placebo 17 patients had a total of 75 attacks (mean $3 \cdot 4(2 \cdot 2)$, range 0-6). Atenolol produced considerable symptomatic relief and 13 patients had no angina while four reported a marked improvement. Four patients complained of fatigue. The total number of anginal attacks was 14 (mean $0.6(0.4)$, range $0-2$, $\mathrm{P}<0.003 v$ placebo).

Eight of the 10 patients with CAD had a total of 19 episodes of angina (mean $1.9(0.6)$, range 0-4) during treatment with placebo. During treatment with atenolol five patients were asymptomatic and five reported a total of six episodes of chest pain (mean $0.6(0.2)$, range $0-2, P<0.02$ ).

Finally, none of the 13 controls had symptoms during placebo treatment, though seven complained of fatigue while on atenolol.

\section{RESTING HAEMODYNAMIC INDICES AND ECG}

In the three groups resting heart rate and blood pressure were similar and were not significantly affected by placebo. In all three groups they were reduced by atenolol to a similar extent (table 1).

On placebo, thirteen patients with SX and six patients with CAD exhibited repolarisation abnormalities such as flat or inverted $T$ waves on the resting ECG. Nine patients with SX and four patients with CAD had completely normal ECGs on atenolol. 
A

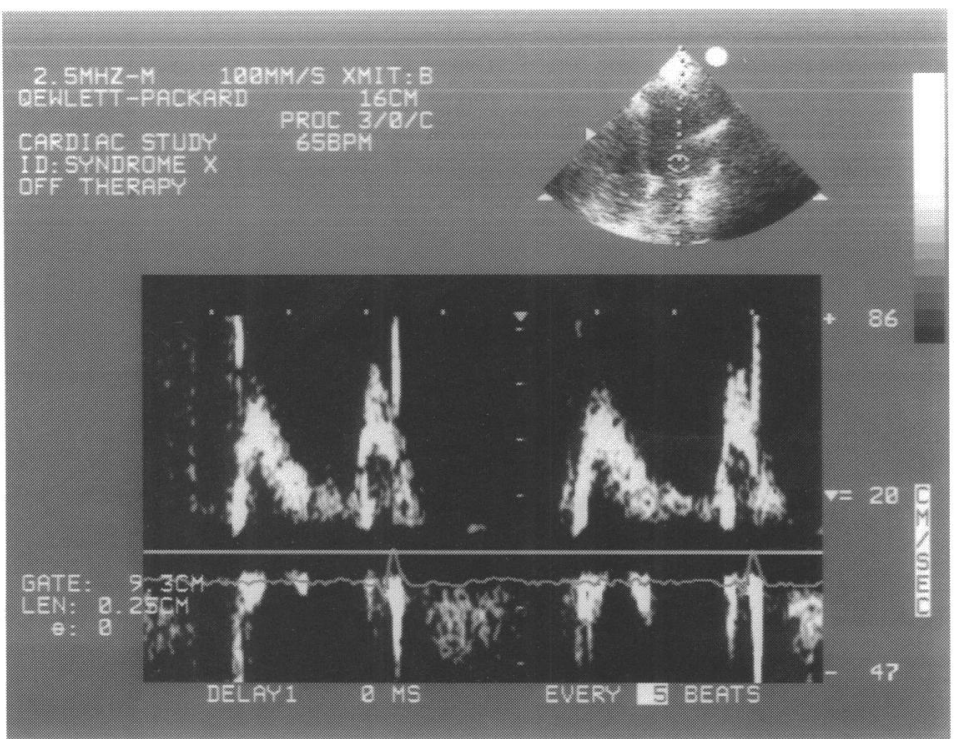

B

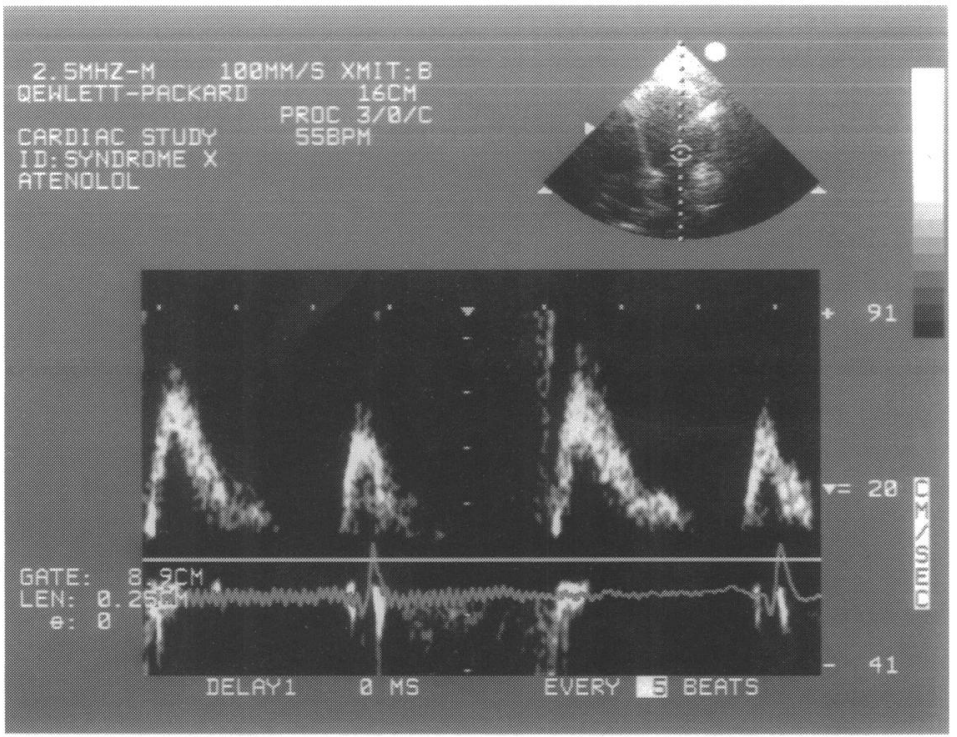

C

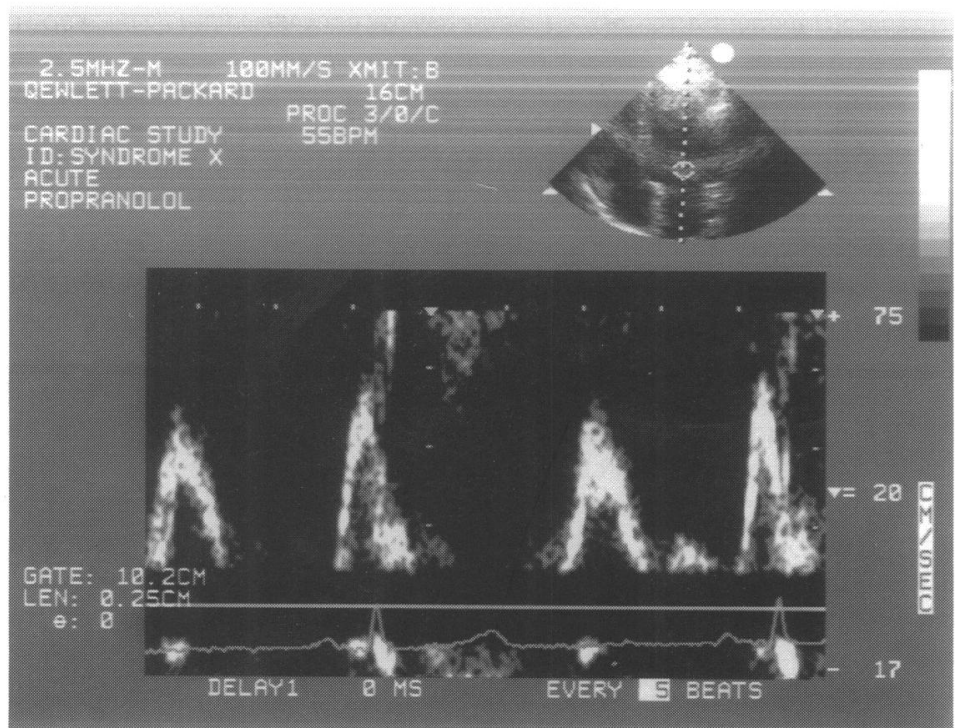

Figure 3 Doppler mitral flow profiles in a syndrome $X$ patient. Off therapy $(A)$ there is a typical abnormal waveform, with $E / A$ ratio $<1$. After 10 days on atenolol (B) there is a marked increase of peak velocity in the rapid filling phase and a decrease of peak velocity of atrial systole with a consequent normalisation of the E/A ratio. Despite a similar heart rate reduction no significant changes are observed after acute $\beta$ blockade with propranolol (C).

EXERCISE TESTING

All patients with SX or CAD had diagnostic ST segment depression during the exercise test performed on placebo. This was associated with chest pain in four $(18 \%)$ and seven $(70 \%)$ patients respectively.

On atenolol, 18 patients with $S \mathrm{X}$ and two patients with CAD did not develop diagnostic ECG changes with exercise. Angina occurred in three and one patients respectively.

All controls had a negative exercise test, both off and on atenolol. Table 2 shows detailed ergometric results in the three groups.

\section{ECHOCARDIOGRAPHY}

The left ventricular mass index (LVMI) was $100(18) \mathrm{g} / \mathrm{m}^{2}$ in SX patients, $122(25) \mathrm{g} / \mathrm{m}^{2}$ in CAD patients, and 89 (18) $\mathrm{g} / \mathrm{m}^{2}$ in controls. Both SX $(P=0.05)$ and CAD $(P=0.004)$ patients had a greater LVMI than controls. A significant difference in LVMI was also found between CAD and SX patients $(P=0.01)$. No changes were observed after atenolol in all groups. Resting ejection fraction was $62(9 \%)$ on placebo and $67(6 \%)$ on atenolol $(P=N S)$ in SX patients, 66 (12) $v 63(11 \%)(\mathrm{P}=\mathrm{NS})$ in CAD patients, and 70 (10) $v 61$ (13\%) $(P=0.03)$ in normal controls. No resting or exercise-induced wall motion abnormalities were present in SX patients and normal controls.

On placebo, seven patients with CAD had resting abnormal wall motion in $2.5(0.5) \mathrm{seg}$ ments, which further deteriorated after exercise. Exercise-induced worsening of wall motion abnormalities was prevented by atenolol in five patients. The remaining three developed new wall motion abnormalities with exercise that were prevented by atenolol in two.

\section{DOPPLER ECHOCARDIOGRAPHY}

The mean values of the calculated variables are shown in table 3. Sixteen SX patients $(70 \%)$ and nine $\mathrm{CAD}$ patients $(90 \%)$ showed an abnormal $(<1)$ resting $\mathrm{E} / \mathrm{A}$ ratio. On average, this variable was significantly lower in SX $(P<0.01)$ and CAD $(P<0.01)$ patients than in controls (fig1). Although total transmitral flow was similar in the three groups, peak early diastolic flow velocity was less in SX $(\mathrm{P}<0.005)$ and $\mathrm{CAD}(\mathrm{P}<0.005)$ patients than in controls. On placebo the time/velocity integrals of early and late diastolic flow were 9.5 $(2.7)$ and $6.4(1.3) \mathrm{cm}$ in SX patients, 9.0 (3.2) and $7 \cdot 8(1.9) \mathrm{cm}$ in CAD patients, and $12.9(4.7)$ and $5.8(2.2)$ in controls $(P<0.004$ for both variables, $\mathrm{CAD}$ and $\mathrm{SX} v$ controls). Accordingly, the atrial contribution to total left ventricular filling was greater in SX $(P<0.03)$ and CAD $(P<0.004)$ patients than in controls (fig 2).

During chronic beta blockade the E/A ratio was within the normal limits in $18 \mathrm{SX}$ patients and in six with CAD. However, although significantly better than during placebo treatment, this variable was still significantly lower in $\mathrm{SX}(\mathrm{P}<0.05)$ and $\mathrm{CAD} \quad(\mathrm{P}<0.01)$ patients than in controls. The increment of the E/A ratio was determined by both an increase in $E$ peak velocity and a decrease in peak $A$ velocity. In controls, atenolol did not induce significant changes of the E/A ratio. The 

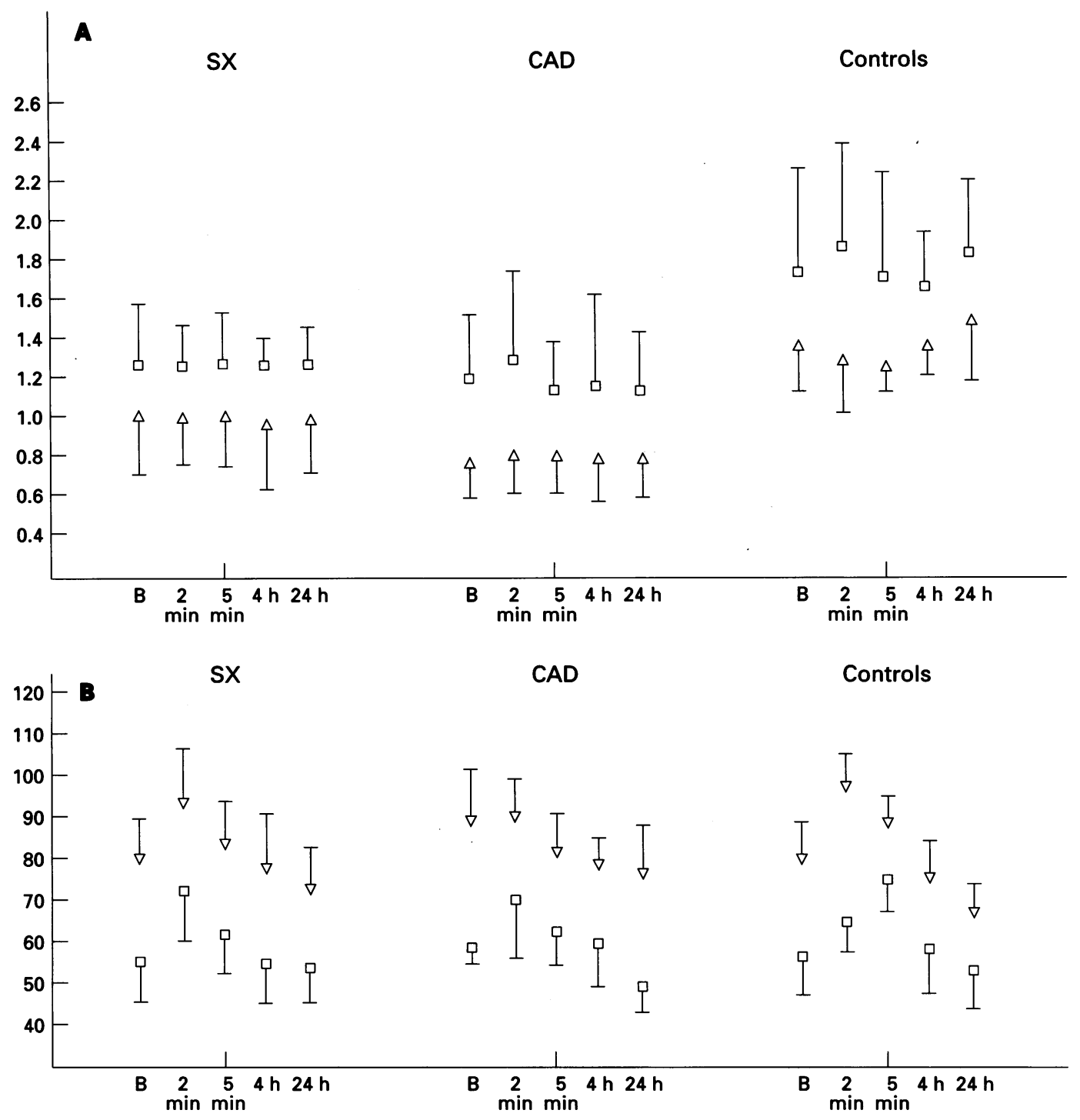

Figure 4 Mean and standard deviation values of the $E / A$ ratio $(A)$ and of heart rate $(B)$ during placebo (open triangle) and during treatment with atenolol (open square), measured before exercise and 2 min, 5 min, $4 h$, and $24 h$ after in the three study groups. The mean $E / A$ ratios $<1$ during placebo and $>1$ during atenolol are not modified by the different heart rates at which they are measured.

time/velocity integrals of early and late diastolic flow also improved in SX and CAD patients but remained practically unchanged in controls. Accordingly, a greater reduction in the atrial contribution to left ventricular filling was observed in SX $(P<0.01)$ and CAD $(P<0.005)$ patients.

Compared with placebo none of the above Doppler variables was significantly affected after acute propranolol administration in any of the study subjects (table 3 ), despite a reduction in heart rate that was similar to that seen during long term treatment with oral atenolol (table 1, fig 3).

Finally, exercise did not induce any significant change in the Doppler flow pattern in any of the three groups. Indeed, after the exercise test, $(2 \mathrm{~min}, 10 \mathrm{~min}, 4 \mathrm{~h}$, and $24 \mathrm{~h}$ ) the E/A ratio did not change significantly and remained stable during the whole study period independently of the heart rate at which it was determined (fig 4).

\section{Discussion}

LEFT VENTRICULAR FILLING ABNORMALITIES IN SYNDROME X: COMPARISON WITH PATIENTS WITH OBSTRUCTIVE CAD

Previous studies assessing left ventricular function in patients with chest pain and normal coronary arteries have reported conflicting results. ${ }^{2-4-12} \mathrm{~A}$ recent investigation failed to show measurable signs of left ventricular systolic dysfunction during or immediately after exercise, in spite of the occurrence of angina, ST segment depression, and occasionally lactate production. ${ }^{12}$ Our results confirm the absence of abnormalities in regional wall motion both at rest and immediately after exercise, but show that most of the Doppler indices of resting diastolic function are frankly abnormal in most patients with syndrome X. Similarly, and in accord with previous observations, ${ }^{15-18}$ resting left ventricular filling was also impaired in some patients with significant coronary artery disease. 
Left ventricular filling abnormalities may result from a variety of mechanisms: these include myocardial hypertrophy and fibrosis, which both affect ventricular compliance, ${ }^{15-1719-21}$ and transient ischaemia, which impairs early diastolic relaxation and alters ventricular filling and the diastolic pressurevolume relation..$^{22-25}$ However, in the absence of these conditions, and especially when systolic function is normal, impairment of diastolic function is difficult to explain.

In our study, patients with SX and CAD had significantly greater left ventricular mass than normal controls. In the absence of obvious ECG and echocardiographic signs of hypertrophy, this finding is hard to interpret: subtle fibrosis resulting from repetitive ischaemia causing a stiffer ventricle is a possible cause. However, whatever the mechanism, increased left ventricular mass does not appear directly to influence Doppler filling variables in trained athletes ${ }^{26}$ or patients with hypertension ${ }^{28} 29$ and hypertrophic cardiomyopathy. ${ }^{30}$ Additionally, in our patients with SX and CAD, LVMI was not affected by atenolol, which, by contrast, markedly improved transmitral flow in most subjects. Therefore, the slight increase in LVMI that we observed in CAD and SX patients is unlikely to be the main determinant of the diastolic filling abnormalities that we found in our study.

Conversely, periods of myocardial ischaemia are known to produce changes in left ventricular relaxation and filling which may persist well beyond recovery of normal systolic function..$^{31}$ Therefore, repetitive periods of ischaemia that are asymptomatic and clinically inapparent may well have a cumulative effect and result in sustained alterations in left ventricular relaxation and filling. Certainly this could explain the impairment of left ventricular filling that we found in patients with coronary disease. It could also account for the alterations in left ventricular compliance that we recorded in patients with angina and angiographically normal coronary arteries - if their condition was at least partially a reflection of myocardial ischaemia.

Diastolic function in patients with $\mathrm{CAD}$ has been previously shown to deteriorate, rapidly and persistently, after exercise-induced ischaemia. ${ }^{32}$ In this study, serial Doppler determinations of left ventricular diastolic filling, did not show significant changes of any of the estimated variables (fig 4). This is in keeping with previous observations based on Doppler echocardiography and obtained during exercise-induced ischaemia. ${ }^{33}$ The reasons for this finding are also not completely clear because throughout the cardiac cycle transmitral flow velocity is the result of several haemodynamic factors that determine the pressure gradient across the mitral valve. Among these factors left atrial pressure plays a major part, and haemodynamic data show that early diastolic filling during exercise-induced ischaemia is maintained at the expense of left atrial pressure. ${ }^{34}$
EFFECT OF $\beta$ BLOCKERS ON ANGINA AND LEFT VENTRICULAR FILLING IN PATIENTS WITH SX AND CAD

In spite of a host of investigations, the pathophysiology of syndrome $\mathrm{X}$ remains largely unknown. Although many studies have shown that a limitation in coronary flow reserve contributes to the syndrome, the relevance and the causes of this limitation are still elusive and may be different in different patients. Some have proposed endothelial dysfunction as a potential mechanism, ${ }^{35-37}$ while others have suggested that $\alpha$-mediated adrenergic constriction may play a part. ${ }^{38-40}$

The results of our study confirm the beneficial effects of $\beta$ blockers in syndrome X. ${ }^{38-40} \mathrm{In}$ fact, while on atenolol, 13 patients reported complete disappearance of anginal episodes, and the remaining nine had a marked improvement. The effect of $\beta$ blockade on the response to maximal exercise was even more striking: the exercise ECG became normal in almost all patients. Similarly, and as in previous studies, atenolol improved anginal symptoms and exercise tolerance in patients with chronic stable CAD ${ }^{41}$ While in the latter coronary flow reserve is limited by the presence of obstructive epicardial coronary disease, in syndrome $\mathrm{X}$ vasodilator capacity may be impaired because of microvascular dysfunction.

Atenolol also improved left ventricular filling in patients with $S X$ and in those with $\mathrm{CAD}$. In the latter, the effect was probably due to the reduction of myocardial oxygen consumption improving the myocardial supply/demand ratio and preventing ischaemia.

A similar mechanism could also operate in patients with SX, though to a lesser extent. Furthermore, the possibility that, in both groups, this $\beta_{1}$ selective agent may have reduced $\alpha$-mediated coronary vasoconstriction through a decrease of the overall sympathetic outflow to the heart cannot be completely disregarded. ${ }^{40}$

Indeed, the pathophysiological role of the sympathetic nervous system in chronic stable angina is well established. ${ }^{42-44}$ The documented efficacy of $\beta$ blockers ${ }^{38} 39$ and the observed hypersensitivity of the coronary circulation to adrenergic stimuli ${ }^{40}$ suggests that increased sympathetic activity may well also play a significant pathophysiological role in the syndrome of angina and normal coronary arteries. In fact, adrenergic overactivity may cause excessive stimulation of both $\beta$ and $\alpha$ receptors. The former increase myocardial demand, whereas the latter may limit the increase in coronary blood flow by causing arteriolar constriction.

It might be argued that the changes in transmitral Doppler flow velocities observed during treatment with atenolol could be simply attributed to the reduced heart rate, because a progressive reduction of the E/A ratio is observed when the heart rate is increased. ${ }^{45}$ However, the E/A ratio was stable at different heart rates in all study subjects, during both placebo and atenolol treatment (fig 4). Furthermore, in patients with SX and in those with CAD acute $\beta$ blockade by pro- 
pranolol did not significantly affect any of the Doppler variables, though the heart rate was reduced to a similar extent as during longterm atenolol treatment. This may suggest that adrenergic blockade has to operate for a long time to allow normalisation of left ventricular filling.

\section{LIMITATIONS OF THE STUDY}

Certainly, the calculation of the LV pressurevolume relation would had been very helpful to characterise better the diastolic function in our patients. However, invasive assessment of diastolic properties would have required recatheterising our patients after chronic $\beta$ blockade. Obviously, this would have been unacceptable for ethical reasons. This is why diastolic function in this study was evaluated by non-invasive means.

Left ventricular diastolic function is a complex phenomenon, resulting from the intrinsic properties of the cardiac muscle, left ventricular systolic function, and the loading conditions of the ventricle. This has to be carefully considered when analysing diastolic indexes derived from the Doppler flow velocity waveform, a feature much influenced by several haemodynamic variables. Therefore, although our findings suggest that patients with syndrome $\mathrm{X}$ and coronary artery disease exhibit similar alterations of the diastolic filling velocity pattern, we cannot be certain that in both conditions these alterations are attributable to the same mechanism-namely, ischaemia. In using intravenous propranolol to correct for heart rate changes, we compared the acute administration of a non-selective $\beta$ blocker with the long-term administration of a selective one. It is therefore not unconceivable that the observed differences between the two treatments may be not entirely due to the duration of $\beta$ blockade but to the possible additional involvement of $\beta_{2}$ antagonism induced by propranolol.

Finally, the atenolol-induced changes in resting transmitral flow pattern may depend on a rise in left atrial pressure. However, because atenolol did not cause any significant $\mathrm{E} / \mathrm{A}$ changes in controls and improved symptoms and exercise tolerance in both SX and CAD groups, it is most unlikely that an increase in left atrial pressure could in itself be responsible for the observed trend towards normalisation of the transmitral flow pattern in the SX and CAD groups. Furthermore, the fact that acute treatment with propranolol did not induce any significant E/A ratio changes, is an additional challenge to the hypothesis that an increase in left atrial pressure could be the main determinant of the improvements seen after atenolol.

We thank Ms Orietta Parmesan and Ms Elena Sala for secretarial assistance and Fabrizio Veglia and Cecilia Gobbi for statistical advice.

$1 \mathrm{Kemp}$ HG. Left ventricular function in patients with anginal syndrome and normal coronary arteriograms. Am $f$ Cardiol 1973;32:375-6.

2 Dwyer EM, Wiener L, Cox JW. Angina pectoris in patients with normal and abnormal coronary arteriograms: hemodynamic and clinical aspects. Am $\mathcal{F}$ Cardiol 1969;23: 639-46.
3 Arbogast R, Bourassa MG. Myocardial function during atrial pacing in patients with angina pectoris and normal coronary arteriograms: comparison with patients havin significant coronary artery disease. $A m f$ Cardiol 1973;32:257-63.

4 Mammohansingh P, Parker JO. Angina pectoris with normal coronary arteriograms: hemodynamic and metabolic response to atrial pacing. Am Heart $\mathcal{F} 1975 ; 90: 555-61$.

5 Opherk D, Zebe H, Weihe E, Mall G, Durr C, Gravert B, et al. Reduced coronary dilatory capacity and ultrastructural changes of the myocardium in patients with angina pectoris but normal coronary arteriograms. Circulation 1981;63:817-25.

6 Cannon RO III, Watson RM, Rosing DR, Epstein SE Angina caused by reduced vasodilator reserve of the small coronary arteries. F Am Coll Cardiol 1983;1: 1359-73.

7 Gibbons RJ, Lee KL, Cobb F, Jones RH. Ejection fraction response to exercise in patients with chest pain and normal coronary arteriograms. Circulation 1981;64:952-7.

8 Cannon RO, Bonow RO, Bacharach SL, Green MV Rosing DR, Leon MB, et al. Left ventricular dysfunction in patients with angina pectoris, normal epicardial coronary arteries and abnormal vasodilator reserve. Circulation 1985;71:218-26.

9 Schofield PM, Brooks ND, Bennett DH. Left ventricular dysfunction in patients with angina pectoris and normal coronary angiograms. Br Heart $\mathcal{f} 1986 ; 56: 327-33$.

10 Schofield PM, Brooks NH, Colgan S, Bennett DH, Whorwell PJ, Bray CL, et al. Left ventricular function and oesophageal function in patients with angina pectoris and normal coronary angiograms. Br Heart $\mathcal{f} 1987 ; 58$ : 218-24.

11 Favaro L, Caplin JL, Fettiche J, Dymond DS. Sex differences in exercise induced left ventricular dysfunction in patients with syndrome X. Br Heart $₹$ 1987;57:232-6.

12 Nihoyannopoulos P, Kaski JC, Crake T, Maseri A Absence of myocardial dysfunction during stress in patients with syndrome X. F Am Coll Cardiol 1991;18: 1463-70.

13 Devereux RB, Reichek N. Echocardiographic determination of left ventricular mass in man. Circulation 1977; 55:613-8

14 Teichholz LE, Kreulent T, Herman MV, Gorlin R. Problems in echocardiographic volume determinations: echocardiographic-angiographic correlations in the presence or absence of asynergy. Am $f$ Cardiol 1976;37:7-11.

ence or absence of asynergy. Am $\mathcal{F}$ Cardiol 1976;37:7-11.
15 Bristow JD, Van Zee BE, Judkins MP. Systolic and diastolic abnormalities of the left ventricle in coronary artery disease: studies in patients with little or no enlargemen of ventricular volume. Circulation 1970;42:219-28.

16 Diamond G, Forrester JS. Effect of coronary artery disease and acute myocardial infarction on left ventricular compliance in man. Circulation 1972;45:11-9.

17 Gibson DG, Prewitt TA, Brown DJ. Analysis of left ventricular wall movement during isovolumic relaxation and its relation to coronary artery disease. Br Heart $\mathcal{F} 1976$; 38:1010-9.

18 Bonow RO, Bacharach SL, Green MV, Kent KM, Rosing $\mathrm{DR}$, Lipson LC, et al. Impaired left ventricular diastolic filling in patients with coronary artery disease: assessment willing in patients with coronary artery disease: assessment with radio. 23 .

19 Mirsky I, Cohen PF, Levine JA, Gorlin R, Herman AV, Kreulen TH, et al. Assessment of left ventricular stiffness in primary myocardial disease and coronary artery disease. Circulation 1974;50:128-36.

20 Gaasch WH, Levine HJ, Quinones MA, Alexander JK. Left ventricular compliance: mechanisms and clinical implications. Am f Cardiol 1976;38:645-53.

21 Grossman W, McLaurin LP. Diastolic properties of the left ventricle. Ann Intern Med 1976;84:316-26.

22 McLaurin LP, Rolett EL, Grossman W. Impaired left ventricular relaxation during pacing induced ischemia. $A m \mathcal{F}$ Cardiol 1973;32:751-7.

23 Mann T, Goldberg S, Mudge GH, Grossman W. Factors contributing to the altered left ventricular diastolic properties during angina pectoris. Circulation 1979;59:14-20.

24 Frist WH, Palacios I, Powell WJ Jr. Effect of hypoxia on myocardial relaxation in isometric cat papillary muscle. $\mathcal{F}$ Clin Invest 1978;61:1218-24.

25 Paulus WJ, Serizawa T, Grossman W. Altered left ventricular diastolic properties during pacing-induced ischemia in dogs with coronary stenoses: potentiation by caffeine. Circ Res 1982;50:218-27.

26 Nixon JV, Wright AR, Porter TR, Roy V, Arrowod JA. Effects of exercise on left ventricular diastolic performance in trained athletes. Am 7 Cardiol 1991;68:945-9.

27 Stork TV, Mockel M, Eichstadt H, Muller RM, Hochrein $\mathrm{H}$. Noninvasive assessment by pulsed Doppler ultrasound of left ventricular filling behavior in long distance sound of left ventricular filling behavior in long distance runner durit

28 Phillips RA, Goldman ME, Ardeljan M, Arora R, Eison HB, Buyan Y, et al. Determinants of abnormal left ventricular filling in early hypertension. $\mathcal{F} \mathrm{Am}$ Coll Cardiol 1989;14:979-85.

29 Verdecchia P, Schillaci G, Guerrieri M, Boldrini F, Gatteschi C, Benemio G, et al. Prevalence and determinants of left ventricular diastolic filling abnormalities in an unselected hypertensive population. Eur Heart 7 1990;11:679-91.

30 Spirito P, Maron BJ. Relation between extent of left ventricular hypertrophy and diastolic filling abnormalities in 
hypertrophic cardiomyopathy. $\mathcal{A}$ Am Coll Cardiol 1990;15: 808-13.

31 Heyndricks G, Millard WR, McRitchie RJ, Maroko PR, Vatner SF. Regional myocardial function and electrophysiological alterations after brief coronary artery occluphysiological alterations after brief coronary artery occ.
sion in conscious dogs. $\mathcal{F}$ Clin Invest $1975 ; 56: 978-85$.

32 Fragasso G, Benti R, Sciammarella M, Rossetti E, Savi A, Gerundini P, et al. Symptom-limited exercise testing causes sustained diastolic dysfunction in patients with coronary disease and low effort tolerance. $\mathcal{f} \mathrm{Am}$ Coll Cardiol 1991;17:1251-5.

33 Presti CF, Walling AD, Montemayor I, Campbell JM, Crawford $\mathrm{MH}$. Influence of exercise-induced myocardial ischemia on the pattern of left ventricular diastolic filling a Doppler echocardiographic study. $7 \mathrm{Am}$ Coll Cardiol 1991;18:75-82.

34 Carroll JD, Hess OM, Hirzel HO, Krayenbuehl HP Dynamics of left ventricular filling at rest and during exercise. Circulation 1983;68:59-67.

35 Vrints C, Bult H, Hitter E, Herman AG, Snoeck JP Impaired endothelium dependent coronary vasodilation in patients with angina pectoris and normal coronary arteriograms. F Am Coll Cardiol 1992;19:21-3

36 Egashira $\mathrm{K}$, Inou $\mathrm{T}$, Hirooka $\mathrm{Y}$, Yamada A, Urabe $\mathrm{Y}$, Takeshita A. Evidence of impaired endothelium-dependent coronary vasodilatation in patients with angina pectoris and normal coronary angiograms. $N$ Engl $f \mathrm{Med}$ 1993;328:1659-64.

37 Motz W, Vogt M, Rabenay O, Scheler S, Luckhoff A, Straver BE Evidence of endothelial dysfunction in coronary resistance vessels in patients with angina pectoris and normal coronary angiograms. Am f Cardiol 1991;68: 996-1003.

38 Romeo F, Gaspardone A, Ciavolella M, Gioffre' P, Reale A. Verapamil versus acebutolol for syndrome $\mathrm{X} . A m \mathfrak{f}$ Cardiol 1988;62:312-3.

39 Bugiardini R, Borghi A, Biagetti L, Puddu P. Comparison of verapamil versus propranolol therapy in syndrome X. $A m$ verapamil versus propranolo

40 Montorsi P, Fabbiocchi F, Loaldi A, Annoni L, Polese A, De Cesare N, et al. Coronary adrenergic hyperreactivity in patients with syndrome $\mathrm{X}$ and abnormal electrocardiogram at rest. $A m \mathcal{F}$ Cardiol 1991;68:1698-703.

41 Chierchia S, Gerosa S, Glazier JJ. Beta-blockers for the treatment of angina pectoris: indications in relation to pathophysiological mechanisms. If Cardiovasc Pharmacol 1987;10:S29-S33.

42 Heusch G, Deussen A. The effects of cardiac sympathetic nerve stimulation on perfusion of stenotic coronary arteries in the dog. Circ Res 1983;53:8-15.

43 Brown BG, Lee AB, Bolson EL, Dodge HT. Reflex constriction of significant coronary stenoses as a mechanisms striction of significant coronary stenoses as a mechanisms
contributing to ischemic left ventricular dysfunction durcontributing to ischemic left ventricular dysfunction
ing isometric exercise. Circulation 1984;70:18-24.

44 Chierchia S, Muiesan L, Davies A, Balasubramian V, Gerosa S, Raftery EB. Role of the sympathetic nervous system in the pathogenesis of chronic stable angina. Circulation 1990;82:II71-II81

45 Smith SA, Stoner JE, Russel EA, Sheppard JM, Aylward PE. Transmitral velocities measured by pulsed Doppler in healthy volunteers: effect of acute changes in blood pressure and heart rate. Br Heart f 1989;61:344-7. 